\title{
Challenges and Opportunities of Global Entrepreneurship and its Impact on Developing Country
}

\author{
Ms. N. Paramesswari \\ Assistant Professor, KG College of Arts and Science, Coimbatore, Tamil Nadu, India
}

\begin{abstract}
Global entrepreneurship is considered to be a characteristic which should be found in a global leader. Global entrepreneurs are those individuals who have global knowledge and understanding along with a global network which they use to identify transnational prospects to utilize in to value creating endeavors. Not all global entrepreneurs belong to profit making businesses; many are excelling in the non-profit world too where they are creating global social enterprises. Some global leaders use global intrapreneurship, where they consume their efforts from within organizations and create more value and global prospects for it (Hisrich, 2010). This research paper will discuss the opportunities and challenges of global entrepreneurship using secondary research data and carrying out a content analysis on how global entrepreneurship is practiced. There are many opportunities that are present in global entrepreneurship for the leader who is operating in and searching for new international markets for their products. The biggest opportunity for the entrepreneur is that the sales of the business or product will likely increase as new markets in the international arena will be explored and this will eventually lead to more growth and profitability. This also helps in decreasing the dependence on the shops of the home country and gives the opportunity to explore a whole new marker of customers with different variety of tastes and demands.
\end{abstract}

\section{INTRODUCTION}

Entrepreneurship is a common word nowadays but with the rise of globalization, global entrepreneurship has also become a well-known word. Global entrepreneurship is the term used for the entrepreneurs who operate on global level and businesses worldwide. Global entrepreneurship plays a key role in businesses today as many entrepreneurs look for multinational corporations to assess their leadership skills. Global entrepreneurship may have many challenges and opportunities that are discussed in this paper along with the ways to face those challenges. It is essential for the entrepreneurs to understand the global nature of the business and the environment they are operating in, in order to be successful.

Global entrepreneurship is advantageous as it can also be taken by the corporate know-how and expertise which is available in other countries. As different companies have different labor markets and different set of ideas are present, there can be more variations and more innovative ideas for business products and marketing. By entering the field of global entrepreneurship, an entrepreneur enters the foreign lands to operate their businesses there. This gives them the opportunity to have a good know-how of all the local trends and demands that are present in that country's consumer market. Moreover, it also gives the chance to the entrepreneurs to be able to learn the systems of the foreign markets and learn the tactics and strategies to compete in these markets.

Global entrepreneurship creates many opportunities for entrepreneurs to take advantage of the labor, manufacturing, and raw materials costs. If the business is being operated in one country, it saves the cost of labor and manufacturing as they hire locals and they take advantage of the low costs of labor and raw materials present in that country. This makes is easier for them to spend more on advertising and attracting the market rather than on their transportation, production, and manufacturing. They benefit from the saving of distribution costs and supplier's costs (Santhi, 2012). It is important that the businesses of today must have complete awareness about the opportunities as well as challenges of global entrepreneurship and this article aims to provide a detailed account of these opportunities and challenges using theoretical base.

\section{Literature Review}

Samli (2009) explains that global entrepreneurship includes value creation by searching for common grounds between different markets or cultures and using those to create a unified effect. Markets can be merged and so can different cultures. Playing on the commonalities, instead of the differences, is their strategy. Samli (2009) further says that organizations that are attempting to bring different cultures on one platform by standardizing their brand promise follow this type of value creation. Examples of such organizations are Nike and McDonald's. Similarly, organizations like Intel try to bring widely applicable and useful technologies to diverse communities (Samli, 2009). Dana (2004) describes another type of value creation through difference creation. Divergence and bringing different elements of cultures to tap new markets is done to make that culture feel welcome and important. In order to enter a distinct and unique market, customizing your strategies and product for them would allow you to provide them what they want instead of what you want them to want. With slight and smart changes, organization and make their products in to multicultural and diverse ones. For example, some of the products made by IKEA are designed in Sweden, and then assembled in China while using African cotton along with Polish plywood.

Casillas (2007) identified the managing control issues and accounts that are included in those challenges that occur in the accounting sector. It not only means that there will be differing accounting standards and methods, it also means that the relationship and communication differences between the organization and the capital providers who may put constraints regarding taking loans locally through financing firms like banks or individual local investors or the 
government. Moreover, Dana (2004) says that inflationaccounting, variances in taxations in different countries, U.S.'s own taxations regarding foreign-source investments, understanding the changes in the corporate income tax and indirect taxes such as withholding taxes, or VAT (value added tax) and other such taxes on varying business transactions are also issues related to the control and accounts (Dana, 2004). Now the second financial issue is related to the risk involved in the changing foreign exchange rate. It requires be monitoring and managing, otherwise the organization could lose a lot of money through it. It is known as the foreign exchange rate exposure, which means the risk that may occur in forthcoming changes that the country's exchange rate may witness that could hurt the firm's operating incomes, according to Dana (2004).

Casillas (2007) further says that new venture do not have a proper infrastructure when they are going global. They face difficulty in disseminated operations with faraway markets. Varying time difference also proves to be a challenge while keeping track of the workweeks of the countries like North America, Europe, China, and India work from Monday to Friday, while Israel works from Sunday to Thursday and UAE and Saudi Arabia's workweek is Saturday till Wednesday and other Muslim nations work from Monday to Saturday. Santhi (2012) identifies another challenge which is the psychic difference which comes from culture, political systems, religion and other such factors. To overcome the rising psychological barriers, entrepreneurs at times take counterintuitive actions. Nations have their separate political, judicial, tax, labor, environmental and regulatory bodies. Every action taken by the entrepreneur affects the shareholder's return on investment and the possibilities of increase in capitals. Dealing with these factors and the mental burden that comes with it is a huge challenge. And to imagine that some entrepreneurs look after not one or two but several different countries simultaneously is mindboggling. The customers of the market have their expectations from the service or the product, even if it is a startup or it has just entered a new market. The entrepreneurs have no choice but to satisfy their needs from day 1 and convert them into loyal customers (Santhi, 2012)

Carraher (2014) says that going global simple gives the entrepreneur an opportunity to benefit from the global status. Many companies adopt global entrepreneurship only to gain the status of operating globally and to gain competitive edge over its competitors as they not only benefit with lower costs of operations but also have a variety of competitive products. Many operations of the business are internationalized and leveraged when a business truly goes global. The entrepreneur is able to provide a variety of products and that too, at reasonable prices. Kshetri (2014) says that governmental or societal problems can also be a reason why an entrepreneur would consider going global an opportunity. Sometimes government regulations and rules are so tough that the entrepreneurs look for other markets and countries to market their products and look for sales. Government interventions and strict laws in operating certain products may lead the entrepreneurs to go global. Moreover, if there is societal tension such as a political outrage or governmental instability which is leading to decrease in consumerism, entrepreneurs consider going global an opportunity to stay away from the regulations (Kshetri, 2014).

\section{Objectives:}

$>$ To study the opportunities of global entrepreneurs

$>$ To identify the challenges in global business

> To know the impact of global issues in developing country

\section{Methodology}

The research is based on qualitative research approach and the selected methodology is secondary analysis of data means that the issues would be explored and understood in detail with the help of information collected from secondary data. The data is collected from several recent journal articles which cover the different challenges and opportunities of global entrepreneurship. This collected information is then analyzed using content analysis methods to explain the position of the global entrepreneurship. The analysis includes strengths, weaknesses, and implication of global entrepreneurship.

\section{Research Findings and Analysis}

The review of the related literature provides detailed understanding about the challenges and opportunities posed by global entrepreneurship. It is revealed that global entrepreneurship may also happen by creation of platforms that support and encourage global exchange. For example, Hong Kong's Global sources have a standard trading platform that is able to single handedly enable trade between Asia and clients all over the world. Their logistics system is extremely strong and encompasses the international value creation through their ports. There are many challenges that are brought in with global entrepreneurship identified by scholars and theorists. These include human resource management issues, control and account issues, exchange policy challenges, cultural issues and other challenges.

It is found that there are various such human management problems that are associated with global businesses. It may be a problem with staffing policies where you require an employee with the perfect mix of cultural and working experience from the host country and the home country. Managing expatriates in home country and managing managers who have been sent to different regions and when they need to repatriate. Understanding the challenges that the expatriates face while they live and work overseas and to make their work life and stay comfortable in that country while appraising, training, managing their development and compensating them is all essential. He furthers that expatriates may get homesick which would start affecting their performance; therefore the Human Resource of a transnational organization has to deal with many factors. Keeping all this in check while making sure that the organization is still the market leader and the employees are motivated and productive, is a hand task that is done on daily basis by global entrepreneurs. The global firms now don't look to be in 24 markets simultaneously. Instead they are looking to have a successful community for the markets they penetrate. Therefore it is essential for them to be market leaders in the markets that they are in rather that to be in every continent. There are multiple types of exposure to the foreign exchange risk of a firm. The first one and the biggest risk is the transaction exposure where the net cash flows from each transaction gets affected by fluxes in the values of foreign exchange. To avoid this, organizations need to create invoice policies and pricing strategies beforehand. There are more risks like translation exposure which is the 
effect that currency exchange rates have on the reported consolidated financial statement or operating exposure which refers to the long term effect of changing exchange rate on future sales, cost and prices. Further there is tax exposure which is different for each country and the interest rate exposure which means the variation and sensitivity to the worth of LIBOR.

The analysis of secondary data further explains that the opportunity for the global entrepreneur is the variety of culture and traditions that they operate it. When going global, there are chances that the companies go through many cultural differences, challenges, and changes which may pose challenges to the company but they are also an opportunity to be able to win the trust of the wide variety of customers. In the global arena, the customers belong to different backgrounds and they prefer the products of those companies that respect cultural values and differences. If a business starts operating in the global arena, being cultural supportive and respective gives them an advantage to create goodwill in the eyes of the customers. The global companies that have cultural variety are more likely to do well and gain customer loyalty from all kinds of customers instead of focusing on one.

Another opportunity is to go to other global places and assess the market. Many times the home market can be declining or aged which gives a negative impact to the businesses operating and a decline in sales. When a business becomes global, it minimizes the risk of a declining market as it has other options and always a chance to utilize its global position to protect the business and gain a new market share. An example is the declining American market sales and sales potential due to its aged demographics. Technological opportunities are another opportunity for the global entrepreneurs when they enter the global market. This is especially true for those entrepreneurs who are going from developing countries to developed countries. They have more opportunities to take advantage of the latest technologies which weren't previously available to them. This can also lead to many opportunities of growth and development for the business as the markets and products are utilizing more and more technological ways to reach the customers and be unique.

\section{Conclusion}

The research study shows that even though there are many opportunities but the challenges of global entrepreneurship cannot be ignored. These challenges can, however, be overcome by certain strategies which help in making global entrepreneurship better for entrepreneurs. In order to address the challenges, the global entrepreneurs should conduct market researches and general researches to assess the requirements and needs of the market before entering it. Research would also give an idea about the cultural differences, trends, different tastes, and the functions of the market. This would give them a direction prior to starting their business. Another way is by creating a comparative analysis about the different government regulations, finances, accounts, control, market risks, costs, suppliers, and others to compare the two countries. A comparative analysis gives a clearer picture of the potential strengths and opportunities that the entrepreneur will be facing. Thus, global entrepreneurship is highly beneficial and it creates value for the business but its challenges and difficulties cannot be ignored. The global entrepreneur has the potential to utilize the global market and global status in the best possible way but if essential prior research is not carried out, the entrepreneur will not be able to benefit from any of it. The opportunities of global entrepreneurship are great and so many entrepreneurs are looking for chances to go global and take advantage of the globalized worlds. Global entrepreneurship is thus, more advantageous and its challenges are clearly overlooked by its opportunities.

\section{References}

[1] Carraher, S. (2014). Global Entrepreneurship. Kendall Hunt Publishing Company

[2] Casillas, J. (2007). International Entrepreneurship in Family Businesses. Edward Elgar Publishing

[3] Dana, L. (2004). Handbook of Research on International Entrepreneurship. Edward Elgar Publishing

[4] Hisrich, R. (2010). International Entrepreneurship: Starting, Developing, and Managing a Global Venture. SAGE

[5] Kshetri, N. (2014). Global Entrepreneurship: Environment and Strategy. Routledge

[6] Samli, C. (2009). International Entrepreneurship: Innovative Solutions for a Fragile Planet. Springer

[7] Santhi, P. (2012). Creativity, Innovation, and Entrepreneurship. Allied Publishers 